\title{
GERMINAÇÃO E MORFOLOGIA DO DESENVOLVIMENTO PÓS-SEMINAL DE SEMENTES DE NIM-INDIANO (Azadirachta indica A. Juss. -MELIACEAE) ${ }^{1}$
}

\author{
DEBORAHDE SOUZA VIDIGAL ${ }^{2}$, BEATRIZ GONÇALVES BRASILEIRO ${ }^{3}$, DENISECUNHA F. S. DIAS ${ }^{4}$, \\ EVELINE MANTOVANI ALVARENGA ${ }^{4}$, MARIA CARMEN BHERING $^{5}$
}

\begin{abstract}
RESUMO - Azadirachta indica A. Juss. é uma espécie nativa das regiões áridas da Ásia e África, mas que atualmente encontra-se distribuída também nas Américas e outras regiões de clima tropical e sub-tropical. É uma planta muito resistente, que apresenta excelentes propriedades medicinais. O objetivo deste trabalho foi definir o tipo de substrato e a temperatura mais adequada à germinação de sementes de nim-indiano (Azadirachta indica A. Juss.) e conhecer a morfologia de seu desenvolvimento pós-seminal, caracterizando as plântulas normais e o tipo de germinação. As sementes foram semeadas nos substratos vermiculita, areia e rolo de papel germitest e mantidas em germinador nas temperaturas de $25^{\circ} \mathrm{C}, 30^{\circ} \mathrm{C}, 35^{\circ} \mathrm{Ce} 20^{\circ} 30^{\circ} \mathrm{C}$. O delineamento estatístico utilizado foi o inteiramente casualizado, com quatro repetições de 25 sementes, avaliando-se a porcentagem de germinação. Os melhores resultados da germinação são verificados na temperatura constante de $35^{\circ} \mathrm{C}$, nos substratos vermiculita e em rolo de papel com contagens de 15 e 30 dias. As plântulas normais são caracterizadas como de germinação epígea.
\end{abstract}

Termos para indexação: Azadirachta indica A. Juss., substrato, temperatura, planta medicinal.

\author{
GERMINATION ANDPOST-SEMINALDEVELOPMENTOFNEEM \\ (Azadirachta indica A. Juss. - MELIACEAE) SEEDS
}

\begin{abstract}
Azadirachta indica A. Juss. is a native specie of the arid areas of Asia and Africa, but nowadays is also distributed in America and other areas with tropical and sub-tropical climate. It is a very resistant plant that presents excellent medicinal properties. The objective of this study was to define the ideal germination conditions for neem (Azadirachta indica A. Juss.) seeds evaluating the most appropriate substrates, temperature and characterizing its post-seminal morphology. Seeds were sown on vermiculite, sand and towel paper and maintained in a germinator at $25^{\circ} \mathrm{C}, 30^{\circ} \mathrm{C}, 35^{\circ} \mathrm{C}$ and $20^{\circ} 30^{\circ} \mathrm{C}$. A complete randomized design was used, with 25 seeds sown in four replications, and the germination percentage was evaluated. The best results were obtained for temperature of $35^{\circ} \mathrm{C}$ in vermiculite and towel paper substrates and countings performed at 15 and 30 days after sowing. Normal seedlings were classified as epigeal germination.
\end{abstract}

Index terms: Azadirachta indica A. Juss., substrate, temperature, medicinal plant.

1 Submetido em 14/11/2006. Aceito para publicação em 22/03/2007.

Mestranda do Programa de Pós-Graduação, Departamento de Fitotecnia da UFV-Viçosa - MG; email: dsvidigal@ gmail.com

3 Doutoranda do Programa de Pós-Graduação, Departamento de Fitotecnia da UFV-Viçosa - MG; email: beatrizgb@univale.br

4 Professores Adjuntos do Departamento de Fitotecnia da Universidade Federal de Viçosa - UFV, 36571-000 - Viçosa - MG; emails: dcdias@ufv.br; eveline@ufv.br

5 Pesquisadora, MS, Departamento de Fitotecnia da UFV-Viçosa-MG; email: mbhering@ufv.br 


\section{INTRODUÇÃO}

O nim (Azadirachta indica A. Juss.) é uma planta da família Meliaceae, nativa das regiões áridas da Ásia e África, mas que atualmente encontra-se distribuída também nas Américas e outras regiões de clima tropical e subtropical (Soon \& Bottrell, 1994). É uma planta muito resistente, de crescimento rápido que alcança, normalmente, de 10 a $15 \mathrm{~m}$ de altura, sendo que a floração e frutificação ocorrem entre três a quatro anos após o plantio (Schumutterer, 1990).

O nim foi usado primeiramente contra pragas caseiras e de armazéns, mas na Índia, seu país de origem, tem uso restrito às pragas da cultura do arroz. Segundo Saxena (1993), a pasta do nim tem sido empregada nas culturas do arroz e da cana de açúcar desde 1930 visando o combate à Diatraea saccharalis e cupim. Frutos, sementes, óleo, folhas, casca do caule e raízes têm os mais variados usos antimicrobianos, nos distúrbios urinários, diarréias e doenças do couro cabeludo. O óleo e seus isolados inibem o desenvolvimento de fungos sobre o homem e animais, e a ação antimalárica é atribuída ao gedunine, um limonóide. Tabletes e injeções contendo em suas formulações extratos de nim são usados no tratamento de malaria crônica (Saxena, 1993).

Todas as partes da planta de nim possuem a substância azadiractina, que afeta mais de 200 espécies de insetos e ácaros (Champagne et al. 1992). A maior concentração de azadiractina encontra-se nas sementes, podendo, em função de fatores como local de origem, idade das sementes e solvente utilizado na extração, ocorrer uma considerável variação nos conteúdos do principio ativo e conseqüentemente na sua atividade biológica (Schumutterer, 1987).

Segundo Hong \& Ellis (1998) as sementes de A. indica, sob condições normais, tem baixa longevidade, exibindo um comportamento intermediário no armazenamento, sendo tolerantes a dessecação e sensível a baixas temperaturas.

O estudo da germinação das sementes de espécies medicinais tem merecido atenção especial da comunidade científica, devido ao incremento ao seu potencial farmacológico, aliado a necessidade de proceder cultivos racionais, destinados a produção de fitoterápico (Pereira, 1992).
Apesar do aumento considerável dos estudos de avaliação da qualidade de sementes de espécies florestais, muitas destas ainda carecem de informações básicas referentes às condições ideais de germinação. Tal afirmação pode ser verificada nas Regras para Análise de Sementes (Brasil, 1992) onde são escassas as recomendações para análise de sementes destas espécies, embora muitas sejam intensamente cultivadas. Este parece ser o caso das sementes de nim, para a qual não se conhecem as condições mais adequadas para a germinação, especialmente a temperatura ótima e o substrato ideal. Tal fato prejudica a avaliação da qualidade das sementes, principalmente quando é necessário comparar resultados obtidos em diferentes laboratórios.

Bewley \& Black (1994) relatam que a temperatura influencia a porcentagem final e a velocidade da germinação, afetando tanto a absorção de água pela semente quanto as reações bioquímicas que regulam o metabolismo envolvido nesse processo.

Os limites extremos de temperatura para germinação fornecem informações de interesse ecológico (Labouriau \& Pacheco, 1978), sendo importante a determinação das temperaturas mínima, ótima e máxima para cada espécie. A temperatura ótima propicia a máxima porcentagem de germinação em menor espaço de tempo, enquanto sob temperaturas máxima e mínima as sementes pouco germinam (Bewley \& Black, 1994).

Sementes de muitas espécies, principalmente as menos domesticadas, requerem flutuação diária de temperatura para germinar adequadamente. Embora esse requerimento esteja associado à superação da dormência da semente, a alternância da temperatura pode acelerar a germinação em sementes não-dormentes (Malavasi, 1988). Muitas espécies tropicais apresentam bom desempenho germinativo na faixa de $20^{\circ} \mathrm{C}$ a $30^{\circ} \mathrm{C}$ (Borges \& Rena, 1993), podendo variar de acordo com as temperaturas encontradas em sua região de origem. Para determinadas espécies, o desempenho germinativo das sementes é favorecido por temperaturas constantes, como em Genipa americana L. (Andrade et al., 2000), por alternância de temperatura, a exemplo de Sebastiania commersoniana (Baill.) Smith \& Downs (Santos \& Aguiar, 2000) e por insensibilidade ao regime de temperatura utilizado, como foi observado nas sementes de Vochysia haenkiana Mart. (Silva et al., 2000). Essas 
características estão diretamente associadas ao comportamento ecológico das espécies nos seus "habitats" (Albuquerque et al., 2003)

O tipo de substrato também influencia os resultados do teste de germinação, já que fatores como aeração, estrutura, capacidade de retenção de água, grau de infestação de patógenos, entre outros, podem variar de acordo com o tipo de material utilizado. A escolha do substrato deve ser feita de acordo com o tamanho e formato da semente, à sua exigência com relação à umidade e à luz, a facilidade que ele oferece durante a instalação, a realização das contagens e a avaliação das plântulas (Brasil, 1992).

Conhecer as condições que proporcionam a germinação rápida e uniforme das sementes é extremamente útil para fins de semeadura e para reduzir os cuidados por parte dos viveiristas, uma vez que as mudas se desenvolverão mais rapidamente, promovendo um povoamento mais uniforme no campo, onde estarão expostas às condições adversas do ambiente (Pacheco et al., 2006).

O objetivo desse trabalho foi estudar os efeitos de diferentes temperaturas e substratos na germinação de sementes de nim (Azadirachta indica A. Juss.) e conhecer o desenvolvimento pós-seminal, caracterizando sua germinação.

\section{MATERIAL E MÉTODOS}

A colheita dos frutos para retirada da semente de nimindiano (Azadirachta indica A. Juss.) foi feita diretamente em árvores plantadas no horto de plantas medicinais da Universidade Vale do Rio Doce, em Governador Valadares, Minas Gerais, quando os frutos, totalmente desenvolvidos, atingiram a coloração verde-amarelada. Os frutos foram levados para o Laboratório de Pesquisa de Sementes da Universidade Federal de Viçosa, onde foram mantidos em condições de ambiente, sendo as sementes retiradas quando os mesmos atingiram a coloração amarela, cerca de três dias após a colheita. Após a extração, as sementes foram submetidas à lavagem em água corrente com a utilização de cal virgem para ajudar na remoção da mucilagem. Após a lavagem, as sementes foram secas em condições de laboratório por dois dias, atingindo 39,66\% de umidade e tratadas com o fungicida Captan, na dosagem de 2,0g (i.a.)/ $\mathrm{kg}$ de sementes. O peso de mil sementes e o número de sementes por quilo foram calculados antes da montagem dos testes.

Os tratamentos, que consistiram das temperaturas e substratos testados, foram distribuídos em delineamento inteiramente casualizado, em esquema fatorial $4 \times 3$, com quatro repetições de 25 sementes. As sementes foram submetidas ao teste de germinação utilizando-se os seguintes substratos: areia - em bandeja plástica $(29 \mathrm{~cm} \times 43 \mathrm{~cm})$, sendo a sementes semeadas em sulcos de $1,0 \mathrm{~cm}$ de profundidade e o substrato umedecido com água destilada até a capacidade de campo; rolo de papel - utilizando três folhas de papel germitest, umedecidas com água destilada na proporção de 2,5 vezes o peso do papel, sendo distribuídas 25 sementes por rolo; e vermiculita - em bandeja plástica $(29 \mathrm{~cm} \times 43 \mathrm{~cm})$, onde as sementes foram semeadas em sulcos de $1,0 \mathrm{~cm}$ de profundidade e o substrato umedecido com água destilada até a capacidade de campo. Foram utilizadas as temperaturas constantes de $25^{\circ} \mathrm{C}, 30^{\circ} \mathrm{C}$, $35^{\circ} \mathrm{C}$ e alternada de $20^{\circ} 30^{\circ} \mathrm{C}$. Na avaliação da germinação as plântulas foram consideradas normais quando estas apresentavam radícula e hipocótilo sadios e desenvolvido, cotilédones abertos e a plúmula presente, e anormal quando este padrão não ocorreu. Foram feitas contagens diárias para estabelecer a data ideal para a primeira contagem e a germinação final das sementes. Foi utilizado o teste de Tukey, a 5\% de probabilidade, para comparação entre as médias.

A descrição morfológica do desenvolvimento pós-seminal foi realizada durante o teste de germinação das sementes e as ilustrações foram feitas em tamanho real, com o auxílio de uma câmara clara.

\section{RESULTADOS E DISCUSSÃO}

\section{Morfologia da semente, do desenvolvimento pós- seminal e da plântula}

A determinação das características físicas revelou sementes com grau de umidade de 39,66\%, peso de mil sementes de 354,8g e 2818 sementes por quilograma.

A espécie Azadirachta indica A. Juss. possui unidades de dispersão constituídas de endocarpo e semente, em geral com comprimento médio de $1,6 \mathrm{~cm}$ e diâmetro médio de 
$0,9 \mathrm{~cm}$. O endocarpo apresenta coloração esbranquiçada, depois de seco, e o tegumento é delgado e de coloração amarronzada. A semente é exalbuminosa, com cotilédones bem desenvolvidos e eixo hipocótilo-radícula reto e curto (Figura 1).

Do ponto de vista morfológico, a germinação iniciou-se ao $6^{\circ}$ dia pelo rompimento do endocarpo e protrusão da radícula (Figura 2a). Verificou-se que a germinação das sementes de nim é do tipo epígea, sendo que o tegumento fica aderido aos cotilédones na fase inicial do crescimento da plântula, onde o eixo hipocótilo-radícula é projetado para fora do substrato. Os cotilédones emergem e se expandem entre o $10^{\circ}$ e o $12^{\circ}$ dia (Figura 2 d e 2 e) e, após um período de crescimento simultâneo do hipocótilo e da raiz principal, aparecem as primeiras raízes secundárias, aproximadamente no $14^{\circ}$ dia (Figura 2f). A plântula normal apresenta raiz principal robusta e poucas raízes secundárias (Figura 2g). O hipocótilo é de coloração branco-esverdeada, cilíndrico e os cotilédones parcialmente expandidos expõem a face convexa evidenciando a germinação epígea. $\mathrm{O}$ epicótilo eleva a plúmula por volta do $15^{\circ}$ dia, que compreende um par de folhas compostas (Figura $2 \mathrm{~h}$ ).

O monitoramento da germinação permitiu o conhecimento do início do desenvolvimento pós-seminal, que foi detectado a partir da emergência da radícula no sexto dia após a semeadura. Com isso pode-se propor uma contagem intermediária aos 15 dias, onde são encontradas plântulas em estádio intermediário de desenvolvimento e a contagem final, quando do estabelecimento da maioria das plântulas normais, que pode ser feita aos 30 dias após a semeadura das sementes de nim.

Segundo as Regras para Análise de Sementes (Brasil, 1992) uma planta normal deve ter todas as suas estruturas essenciais presentes, desenvolvidas e saudáveis como é vista na Figura 2g. Quando este padrão não ocorre as plântulas são classificadas como anormais, resultantes de tratamento a que as sementes foram submetidas, de formação congênita, ou da idade da semente.

\section{Substrato e temperatura}

Os resultados de porcentagem de germinação das sementes de nim em diferentes substratos e temperatura são apresentados na Tabela 1. A partir da interação significativa dos substratos e temperaturas, verificou-se que na temperatura de $35^{\circ} \mathrm{C}$ a germinação obtida nos substratos vermiculita e rolo de papel foram superiores, quando comparados ao substrato areia. Nas demais temperaturas não houve diferença entre os substratos testados, exceto para a temperatura de $30^{\circ} \mathrm{C}$ em que a germinação no substrato rolo de papel foi superior a observada nos demais substratos. No substrato areia as temperaturas não diferiram estatisticamente entre si.

Nos estudos relacionados à metodologia do teste de germinação de espécies florestais, Oliveira et al. (1989) recomendaram o uso de temperaturas alternadas, já que essas simulariam o ambiente natural de florestas, onde as flutuações de temperaturas ocorrem, principalmente, pela abertura de clareiras que estimulam a germinação de espécies pioneiras.

Temperatura de $20^{\circ} 30^{\circ} \mathrm{C}$ e uso de rolo de papel como substrato foram recomendados por Santos et al. (1999) para sementes de Passiflora edulis Sims f. flavicarpa Deg. e por Medeiros et al. (2001) para sementes de Aegiphila sellowiana Cham. Já Santos \& Aguiar (2000) obtiveram melhores resultados de germinação de sementes de Sebastiania commersoniana (Baill.) Smith \& Downs na temperatura alternada de $20^{\circ} 30^{\circ} \mathrm{C}$ e sobre areia.

Silva et al. (2002) trabalhando com sementes de aroeira (Myracrodruon urundeuva Allemão), verificaram que o comportamento germinativo das sementes foi similar para a melhor temperatura constante $\left(20^{\circ} \mathrm{C}\right)$ quando comparados com os obtidos na melhor temperatura alternada $\left(20^{\circ} 30^{\circ} \mathrm{C}\right)$, não havendo efeito significativo do regime de temperatura.

A faixa de temperatura de $25^{\circ} \mathrm{C}$ mostrou-se adequada para condução dos testes de germinação de sementes de Stevia rebaudiana (Bert.) Bertoni. (Takahashi et al., 1996), Gmelina arbórea Roxb. (Cavallari et al., 1992) e Seguieria langsdorffii Moq. (Rêgo et al., 2001); de $30^{\circ} \mathrm{C}$ para sementes de Ocotea corymbosa (Meissn) Mez. (Bilia et al., 1998), Desmodium incanum DC. (Baseggio \& Franke, 1998) e Maquira sclerophylla (Ducke) C.C. Berg. (Miranda \& Ferraz, 1999) e de $35^{\circ} \mathrm{C}$ para sementes de Myracrodruon urundeuva Allemão (Silva et al., 2002).

Neste trabalho, os resultados demonstraram que as sementes de Azadirachta indica A. Juss. não possuem exigência de alternância de temperatura, para acelerar ou 
TABELA 1. Percentagem de germinação de nim (Azadirachta indica A. Juss.) obtida na contagem final (30 dias), em função da temperatura e do substrato.

\begin{tabular}{|c|c|c|c|c|c|}
\hline \multirow[b]{2}{*}{ Substrato } & \multicolumn{4}{|c|}{ Temperatura $\left({ }^{\circ} \mathrm{C}\right)$} & \multirow[t]{2}{*}{ Média } \\
\hline & 25 & 30 & 35 & $20-30$ & \\
\hline Vermiculita & $7 \mathrm{Ba}$ & $6 \mathrm{Bb}$ & $52 \mathrm{Aa}$ & $1 \mathrm{Ba}$ & 16,50 \\
\hline Areia & $5 \mathrm{Aa}$ & $5 \mathrm{Ab}$ & $4 \mathrm{Ab}$ & $3 \mathrm{Aa}$ & 4,25 \\
\hline Rolo de Papel & $9 \mathrm{Ba}$ & $20 \mathrm{Ba}$ & $50 \mathrm{Aa}$ & $11 \mathrm{Ba}$ & 22,50 \\
\hline Média & 7,00 & 10,30 & 35,33 & 5,00 & \\
\hline
\end{tabular}

Na linha, médias seguidas da mesma letra maiúscula e, na coluna, médias seguidas da mesma letra minúscula não diferem entre si, pelo teste de Tukey, a 5\% de probabilidade.

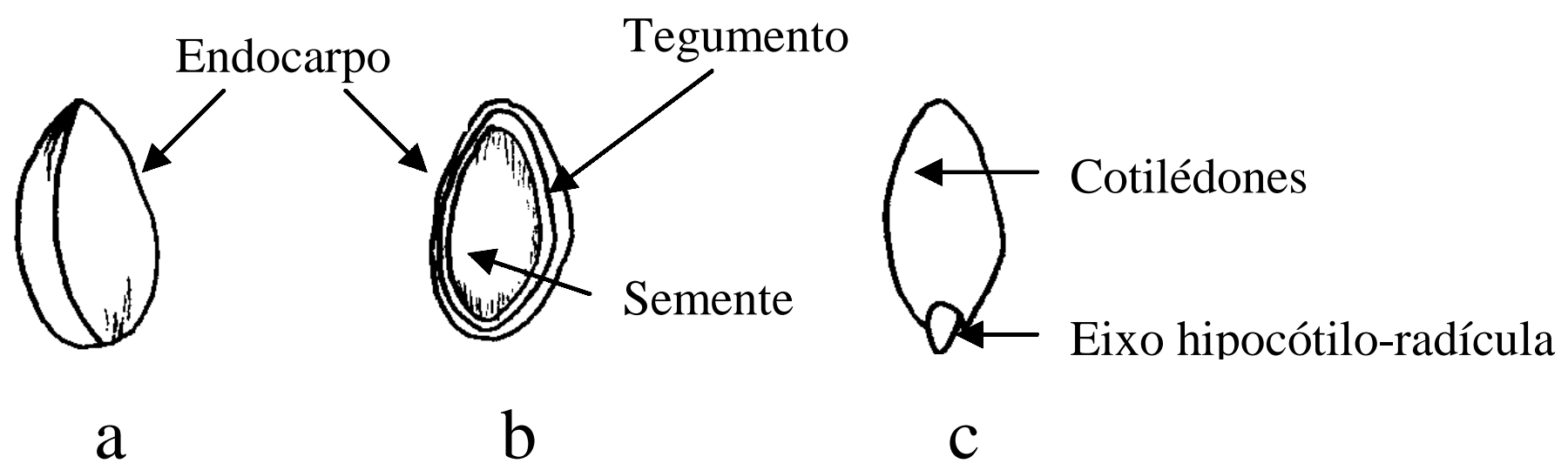

FIGURA 1. Semente de Azadirachta indica A. Juss.: a - morfologia externa. 

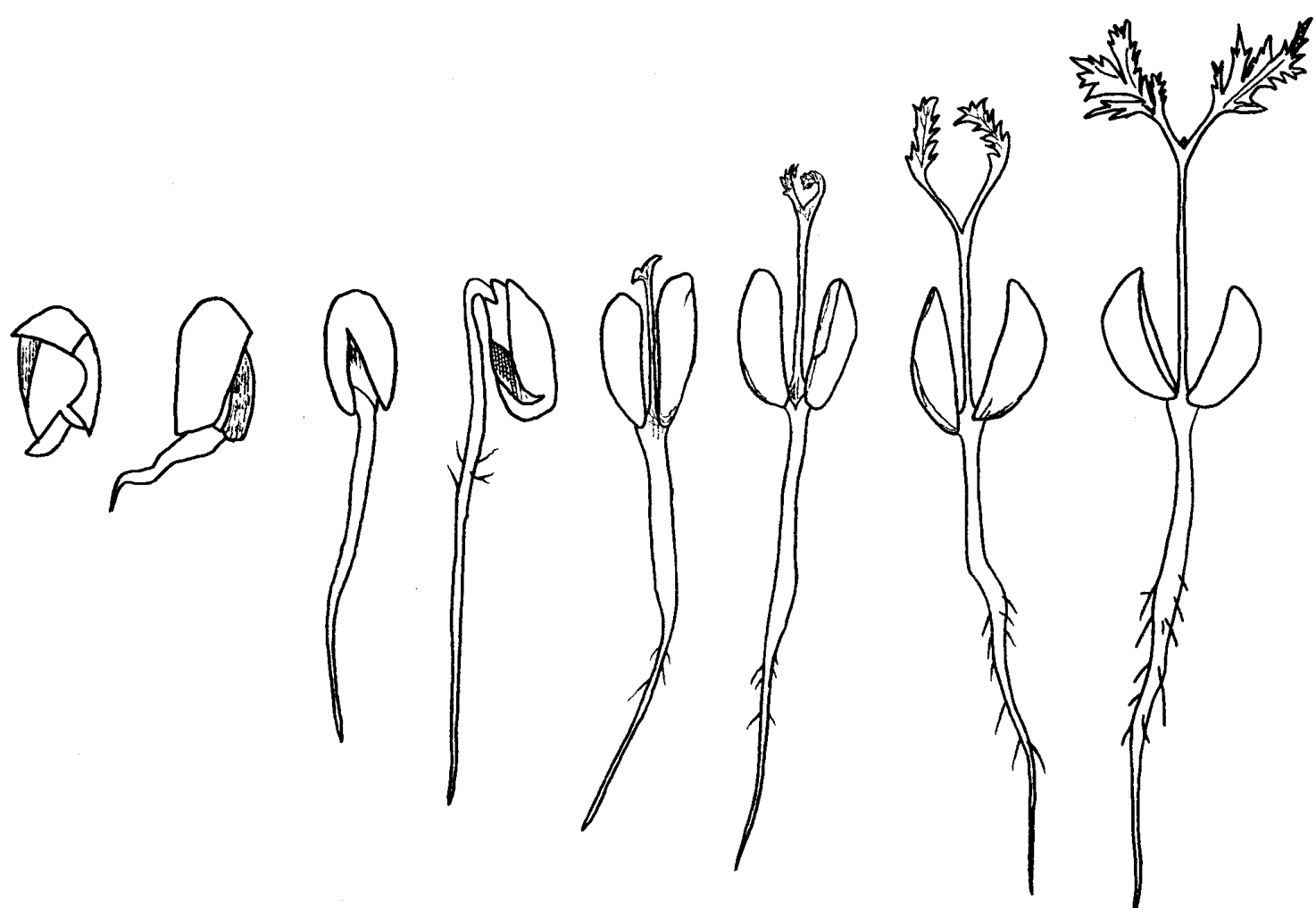

FIGURA 2. Estádios sucessivos do desenvolvimento da plântula de Azadirachta indica A. Juss. durante 30 dias: a-b - protrusão da raiz primária; c-d - rompimento do endocarpo e tegumento; e - abertura dos cotilédones e plântula normal; f - emissão do epicótilo.

iniciar o processo germinativo, uma vez que a porcentagem de sementes germinadas na temperatura alternada $\left(20^{\circ} 30^{\circ} \mathrm{C}\right)$ foi inferior aquela ocorrida em temperatura constante de $35^{\circ} \mathrm{C}$.

Os substratos testados influenciaram a germinação de Azadirachta indica A. Juss. É provável que a capacidade de retenção de água de cada substrato, aliada às características intrínsecas que regulam o fluxo de água para as sementes, possa ter influenciado os resultados. Dos substratos utilizados, a areia foi o que mostrou menor capacidade de retenção de água, e o que se apresentou com a menor média de germinação.

Figliolia et al. (1993) relatam que o substrato areia apresenta o inconveniente de drenar excessivamente a água, ficando a parte superior ressecada. Além disso, é muito pesado e de difícil manuseio no germinador.

Os maiores valores de germinação foram encontrados no substrato vermiculita e rolo de papel. Resultado semelhante foi verificado por Pereira \& Andrade (1994) em sementes de maracujá, onde a germinação apresentou valores superiores para substrato vermiculita atribuindo a alta capacidade de retenção de água e as condições adequadas de aeração da vermiculita às suas propriedades físico-químicas.

\section{CONSIDERAÇÕES FINAIS}

A germinação das sementes de nim é do tipo epígea.

De acordo com os resultados obtidos, podem-se recomendar os substratos vermiculita e rolo de papel germitest e temperatura constante de $35^{\circ} \mathrm{C}$, para o teste de germinação em laboratório para sementes de Azadirachta indica A. Juss. com contagens de 15 e 30 dias.

O substrato areia não é eficiente para germinação de sementes de nim, independente da temperatura utilizada. 


\section{REFERÊNCIAS}

ALBUQUERQUE, M.C.F.; COELHO, M.F.B.; ALBRECTH, J.M.F. Germinação de sementes de espécies medicinais do Cerrado. In: COELHO, M.F.B.; COSTA JÚNIOR, P.; DOMBROSKI, J.L.D. Diversos olhares em etnobiologia, etnoecologia e plantas medicinais. Cuiabá: UNICEN Publicações, 2003. p.157-181.

ANDRADE, A.C.S.; SOUZA, A.F.; RAMOS, F.N.; PEREIRA, T.S.; CRUZ, A.P.M. Germinação de sementes de jenipapo: temperatura, substrato e morfologia no desenvolvimento pós-seminal. Pesquisa Agropecuária Brasileira, Brasília, v.35, n.3, p.609-615, 2000.

BASEGGIO, J.; FRANKE, L.B. Condições para a germinação de sementes de Desmodium incanum DC. Revista Brasileira de Sementes, Brasília, v.20, n.1, p.148-152, 1998.

BEWLEY, J.D.; BLACK, M. Seeds: physiology of development and germination. New York: Plenum Press, 1994. 445p.

BILIA, D.A.C.; BARBEDO, C.J.; MALUF, A.M. Germinação de diásporos de canela-preta (Ocotea corymbosa (Meissn.) Mez Lauraceae) em função da temperatura, do substrato e da dormência. Revista Brasileira de Sementes, Brasília, v.20, n.1, p.189-194, 1998.

BORGES, E.E.L.; RENA, A.B. Germinação de sementes. In: AGUIAR, I.B.; PINÃ-RODRIGUES, F.C.M.; FIGLIOLIA, M.B. Sementes florestais tropicais. Brasília: ABRATES, 1993. p.83135.

BRASIL. Ministério da Agricultura e Reforma Agrária. Regras para análise de sementes. Brasília: SNAD/DNDV/CLAV, 1992.365p.

CAVALLARI, D.A.; WETZEL, M.M.V.S.; BATISTA, L.A.R. Substrato e temperatura na germinação de sementes de Gmelina arborea Roxb. Revista Brasileira de Sementes, Brasília, v.14, n.1, p.89-92, 1992.

CHAMPAGNE, D.E.; KOUL, O.; ISMAN, M.B.; SCUDER, G.G.E.; TOWERS, G.H.N. Biological activity of limonoids from Rutales. Phytochemistry, London, v.31, n.2, p.377-394, 1992.

FIGLIOLIA, M.B.; OLIVEIRA, E.C.; PIÑA-RODRIGUES, F.C.M. Análise de sementes. In: AGUIAR, I.B.; PIÑA-RODRIGUES, F.C.M.; FIGLIOLIA, M.B. (Coord.) Sementes florestais tropicais. Brasília: ABRATES, 1993.p.137-174.

HONG, T.D.; ELLIS, R.H. Contrasting seeds storage behaviour among different species of Meliaceae. Seed Science and Technology, Zürich, v.26, n.1, p.77-95, 1998.

LABOURIAU,L.G.; PACHECO, A. On the frequency of isothermal germination in seeds of Dolichos biflorus L. Plant \& Cell Physiology, Toquio, v.19, n.3, p.507-512, 1978.

MALAVASI, M.M. Germinação de sementes. In: PIÑARODRIGUES, F.C.M. (Coord.). Manual de análise de sementes florestais. Campinas: Fundação Cargill, 1988. p.25-40.
MEDEIROS, A.C.S.; ABREU, D.C.A.; NOGUEIRA, A.C. Efeito da temperatura e do substrato na germinação de sementes de tamanqueiro (Aegiphila sellowiana).In.: CONGRESSO BRASILEIRO DE SEMENTES, 12., 2001, Curitiba. Informativo Abrates, Londrina, v.11, n.2, p.133, 2001. (Resumo , 174).

MIRANDA, P.R.M.; FERRAZ, I.D.K. Efeito da temperatura na germinação de sementes e morfologia da plântula de Maquira sclerophylla (Ducke) C.C. Berg. Revista Brasileira de Botânica, São Paulo, v.22, n.2 (supl.), p.303-307, 1999.

OLIVEIRA, E.C.; PIÑA-RODRIGUES, F.C.M.; FIGLIOLIA, M.B. Propostas para a padronização de metodologias em análise de sementes florestais. Revista Brasileira de Sementes, Brasília, v.11, n.1, p.1-42, 1989.

PACHECO, M.V.; MATOS, V.P.; FERREIRA, R.L.C.; FELICIANO, L.P.; PINTO, K.M.S. Efeito de temperaturas e substratos na germinação de sementes de Myracrodruon urundeuva Fr. All. (Anacardiaceae). Revista Árvore, Viçosa, v.30, n.3, p.359-367, 2006.

PEREIRA, T.S. Germinação de sementes de Bauhinia forficata Link. (Leguminosae-Caesalpinoideae). Revista Brasileira de Sementes, Brasília, v.14, n.1, p.77-82, 1992.

PEREIRA, T.S.; ANDRADE, A.C.S. Germinação de Psidium guajava L. e Passiflora edulis S. - efeito da temperatura, do substrato e morfologia do desenvolvimento pós-seminal. Revista Brasileira de Sementes, Brasília, v.16, n.1, p.58-62, 1994.

RÊGO, G.M.; LIMA, R.M.B.; POSSAMAI, E. Efeito do substrato e da temperatura sobre a germinação e vigor das sementes de pau-de-alho (Seguieria langsdorffii Moq.) - Phytolaccaceae, em laboratório. In.: CONGRESSO BRASILEIRO DE SEMENTES, 12., 2001, Curitiba. Informativo Abrates, Londrina, v.11, n.2, p.256, 2001. (Resumo, 418).

SANTOS, C.M.; SOUZA, G.R.L.; SILVA, J.R.; SANTOS, V.L.M. Efeito da temperatura e do substrato na germinação de sementes do maracujá (Passiflora edulis Sims. f. flavicarpa Deg.). Revista Brasileira de Sementes, Brasília, v.21, n.1, p.1-6, 1999.

SANTOS, S.R.G.; AGUIAR, I.B. Germinação de sementes de branquilho (Sebastiania commersoniana (Baill.) Smith \& Downs) em função do substrato e do regime de temperatura. Revista Brasileira de Sementes, Brasília, v.22, n.1, p.120-126, 2000.

SAXENA, R. C. Scope of nim for developing countries. In: WORLD NIM CONFERENCE SOUVENIR, 1993, Bengalore. Proceedings... Bengalore: [s.n.], 1993. p. 24-28.

SCHUMUTTERER, H. Insect growth-disrupting and fecundityreducing ingredients from the neem and chynaberry trees. In: MORGAN, E.D.; MANDAVA, N.B.(Ed). Handbook of natural pesticides. Washington: CRC, 1987. p.119-167.

SCHUMUTTERER, H. Properties and potential of natural pesticides from the nim tree, Azadirachta indica. Annual Review of Entomology, Palo Alto, v. 35, p. 271-297, 1990. 
SILVA, L.M.M.; RODRIGUES, T.J.D.; AGUIAR, I.B. Efeito da luz e da temperatura na germinação de sementes de aroeira (Myracrodruon urundeuva Allemão). Revista Árvore, Viçosa, v.26, n.6, p.691-697, 2002.

SILVA, V.P.; COSTA, R.B.; NOGUEIRA, A.C.; ALBRECHT, J.M.F. Influência da temperatura e luz na germinação de sementes de cambará (Vochysia haenkiana Mart.). Revista Agricultura Tropical, Cuiabá, v.4, n.1, p.99-108, 2000.
SOON, I.G.; BOTTRELL, D.G. Neem pesticides in rice: potential and limitations. Manila: International Rice Research Institute, 1994. 69p.

TAKAHASHI, L.; MELGES, E.; CARNEIRO, J.W.P. Desempenho germinativo de sementes de Stevia rebaudiana (Bert.) Bertoni sob diferentes temperaturas. Revista Brasileira de Sementes, Brasília, v.18, n.1, p.6-9, 1996.

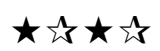

